\title{
Genome-wide association analysis of inguinal/scrotal hernia in pigs using specific length amplified fragment (SLAF) sequencing
}

\author{
Danyang Zou ${ }^{1, *}$, Bo Zuo ${ }^{1,2, *}$, Mingfei Zhu ${ }^{1}$, Lei Rong ${ }^{1}$, Huimin Mao ${ }^{3}$, Hongdan Niu ${ }^{1}$, \\ Ling Wang ${ }^{1}$ and Rong Zheng ${ }^{1}$ \\ ${ }^{1}$ Key Laboratory of Swine Genetics and Breeding of Ministry of Agriculture and Key Laboratory of Agriculture Animal Genetics, \\ Breeding and Reproduction of Ministry of Education, College of Animal Science and Technology, Huazhong Agricultural \\ University, Wuhan, 430070, Hubei, P.R. China \\ ${ }^{2}$ The Cooperative Innovation Center for Sustainable Pig Production, Wuhan, 430070, P.R. China \\ ${ }^{3}$ The Tianpeng Group, Jiangshan, Zhejiang, 324111, P.R. China \\ *These authors share co-first authorship
}

Correspondence to: Rong Zheng, email: zhengrong@mail.hzau.edu.cn

Keywords: GWAS; SLAF-seq; inguinal/scrotal hernia; pig; farmCPU

Received: October 06, $2017 \quad$ Accepted: October 27, 2017

Published: December 22, 2017

Copyright: Zou et al. This is an open-access article distributed under the terms of the Creative Commons Attribution License 3.0 (CC BY 3.0), which permits unrestricted use, distribution, and reproduction in any medium, provided the original author and source are credited.

\section{ABSTRACT}

Inguinal and scrotal hernias are the most frequent congenital disorders in pigs, and they may cause severe economic loss in the pig breeding industry. Genetic factors play a significant role in the susceptibility to hernias, but the genetic mechanisms of inguinal/scrotal hernia are poorly understood. In this study, we performed a genome-wide association study (GWAS) with specific-locus amplified fragment sequencing (SLAF-seq) on 120 (59 cases and 61 controls) full and half sib pigs to identify genetic loci underlying variations in inguinal/scrotal hernias. A total of $\mathbf{2 1 8}, \mathbf{4 6 0}$ high-quality SNPs were generated for further statistical analysis with casecontrols and the farmCPU model. Based on these two methods, a total of 59 SNPs were significantly $(P<0.01)$ associated with inguinal/scrotal hernia. Finally, 14 novel candidate genes implicated in the defect were identified, and 5 genes (CPNE5, DEGS1, PLCG2, PRKCE and NUAK1) were related to cell apoptosis, which is one of the pivotal pathogenesis factors of inguinal/scrotal hernia. In addition, 4 of them were shown strong associations with the hernia were confirmed in 270 samples $(P<0.05)$. This finding provides new evidence that genes related to cell apoptosis may be associated with inguinal/scrotal hernias.

\section{INTRODUCTION}

Inguinal and scrotal hernias, which occur in the weak areas of the inguinal canal $[1,2]$ or the processus vaginalis [3, 4], are some of the most frequent congenital disorders observed in pigs and humans $[5,6]$. They cause severe economic loss in the pig breeding industry [7]. Hernia development is caused by both multiple genes and environmental factors [8]. To date, candidate genes related to the development of inguinal/scrotal hernias have been inspected. A linkage map of 15 porcine STS markers was constructed and the sex determining region Y-box 9 (SOX9), which results in sex hormone deregulation, was identified as a potential candidate gene of pig inguinal/scrotal hernias [9]. Moreover, the collagen type II alpha 1(COL2A1) and matrix metallopeptidase 2 (MMP2) genes have been found to be involved in pig scrotal hernias by promoting aberrant collagen metabolism processes [10]. However, only a few candidate genes have been reported and the molecular mechanism of the etiology remains unclear.

To obtain more effective susceptibility genes, a series of GWAS identifications of inguinal/scrotal hernias have been recently published in several different pig breeds. Four candidate genes (ELF5, KIF18A, COL23A1 and NPTX1) for the defects on Sus scrofa chromosomes (SSC) 2 and 12 were identified from 6 commercial 
pig breeds and there was no overlap in the significant SNPs from different pig breeds [11]; Ding et al. (2009) detected the most remarkable loci on SSC 7, 8, and 10 in a White Duroc $\times$ Erhualian resource population of F2 pigs [12]. Sevillano et al. (2015) identified five distinct QTL regions that strongly affected the inguinal/scrotal hernias detected in both Large White and Landrace datasets [13]. Conclusively, the current study findings showed the putative inheritance mode of inguinal/scrotal hernias was of polygenic effects. Nevertheless, the main genes with important roles were not found. Thus, more high-quality and high-density SNPs were studied among the whole genome to seek the markers observably associated with inguinal/scrotal hernias.

Next-generation sequencing (NGS) technologies have made it possible to obtain high-density SNP markers throughout the entire genome, which was precisely the basis of the GWAS [14-16]. Consequently, several reduced representation sequencing technologies, including restriction site associated sequencing (RADseq), genotyping by sequencing (GBS) were developed for SNP scanning [17]. Specific-locus amplified fragment sequencing (SLAF-seq) is a new efficient and highresolution approach based on reduced representation sequencing for de novo SNPs discovery and large-scale genotyping [18]. Compared with other sequencingbased technologies, the SLAF-seq technology has more advantages in large populations, such as significant cost saving, high capacity of samples, less sequencing demand, and high genotyping accuracy without prior genomic information [19-22] Thus, this method has now been successfully applied to screen for specific molecular markers in many species. Zhao et al. constructed a high-density haplotype map of SNP markers in soybean through SLAF-seq technology and 4 candidate genes were identified for resistance to Sclerotinia sclerotiorum [23]. Zhang et al. performed a GWAS using SLAF-seq to detect the SNP markers that were associated with growth traits in Jinghai Yellow chicken hens [24]. Li et al. developed a SLAF-seq approach to reveal the genetic differences among Landrace, Erhualian, and Meishan pigs [25]. Thus, we used SLAF-seq and GWAS to discover the candidate genes associated with pig inguinal/scrotal hernias in a set of 120 accessions (59 inguinal/scrotal hernia cases and 61 unaffected controls) from four pig populations including French Yorkshire, French Landrace, American Yorkshire and crossbred pigs. These results can be used for subsequent investigations of pig inguinal/scrotal hernias in the hope of eradicating the disease at a molecular level.

\section{RESULTS}

\section{SLAF sequencing and SNP marker screening}

To genotype the 120 pig accessions, SLAF-seq was performed with Illumina $\mathrm{HiSeq}^{\mathrm{TM}} 2500$ (Illumina,
Inc, USA) at Biomarker Technologies Corporation. The restriction enzymes RsaI and HaeIII were selected based on in silico digestion prediction, and it resulted in 332,425 predicted 314-344 bp SLAF tags that were evenly distributed across the whole pig genome. Basing on SLAF library construction and high-throughput sequencing, a total of $110 \mathrm{~Gb}$ raw data including 782.06 $M$ reads were obtained, with each read $100 \mathrm{bp}$ in length and an average depth of $12.81 \mathrm{x}$ from this experiment. The average Q30 ratio (a quality score of 30) and the average guanine-cytosine (GC) content of $85.34 \%$ and $44.36 \%$, respectively, was indicative of good quality (Supplementary Table 1).

A total of 407,274 high-quality SLAF tags were selected to obtain high-quality polymorphic SLAFs after two rounds of sequencing and exclusion of low-quality fragments, and 217,408 polymorphic SLAFs were identified from these reads by sequence alignments with the Sus scrofa reference genome (GenBank Assembly ID GCA_000003025.4 ftp://ftp.ensembl.org/pub/release-80/ fasta/sus_scrofa/dna/). According to the results, SLAF tag numbers were calculated on each chromosome (Supplementary Table 2), and the distribution diagram of SLAF tags involved each chromosome (Figure 1A). The SLAFs were well distributed on each chromosome with high integrity and accuracy. The average coverage in the samples revealed that the sequencing results are reliable for calling SNPs. In total, we initially called 2,514,779 SNPs for quality control, and a large proportion were found to have a minor allele frequency (MAF) of $<0.05$ or low integrity $(<0.8)$ and should be removed. After filtration, 218,460 SNPs, which covered all 20 chromosomes, were used for inclusion in the GWAS (Supplementary Table 3, Figure 1B).

\section{Population structure}

Before conducting the genome-wide association study, the population structure assessed by ADMIXTURE [26] was performed using 218,460 SNPs of the 120 accessions to separate accessions from mixed populations and estimate the number of subgroups, which had great influence on the association analyses between phenotypes and molecular bands. This method is based on a clustering strategy to calculate the cross validation (CV) errors of the large sample sizes, and then the minimum $\mathrm{K}$ value could produce the best dataset. With the maximum membership probability, the best dataset was $\mathrm{K}=3$, which meant the samples were probably derived from 3 ancestors in our study (Figure 2). The result is highly consistent with the sample information, indicating that this swine population could be used for association analysis. Additionally, principal component (PCA) and neighbor-joining cluster analyses were set to verify the evolutionary relationships between the 120 samples. Both the PCA and cluster results showed that all the samples fell mostly into three groups, 
with only a few outliers, which was in accordance with the above results (Figure 3A, 3B).

\section{GWAS analysis}

In an attempt to investigate inguinal/scrotal hernia loci, a GWAS was carried out to search for associated tags and allelic variations. We selected two popular methods (PLINK and farmCPU) to analyze the data.

In PLINK, 7 SNP loci $\left(P<10^{-6}\right)$ were found to be significantly related to inguinal/scrotal hernias according to the case-control mode, and the QQ-plot revealed that there was no obvious population stratification in this experiment. Two of the seven SNP loci (rs327702852, $P=4.82 \mathrm{E}-06$ and rs340140110, $P=8.44 \mathrm{E}-06$ ) overlapped the known genes CPNE5 and $M A P 7 D 2$, respectively (Table 1, Figure 4).

In farmCPU, a total of 52 significant association signals were identified, with $P<8.91 \mathrm{E}-06$, from the disparate threshold (Table 2, Table 3). Both the default and suggestive p.threshold could make a great difference in the association results. Specifically, in trait1, the two significant SNPs (rs319767757, $P=1.24 \mathrm{E}-06$ and rs320497311, $P=2.19 \mathrm{E}-06)$ confirmed in the two p.threshold were located in the known gene $A U H$ (Figure $5 \mathrm{~A}, 5 \mathrm{~B}, 5 \mathrm{G}, 5 \mathrm{H})$. In trait 2 , when p.threshold $=0.01 / \mathrm{N}$ and 1E-05, 9 and 6 remarkable SNPs overlapped the known genes, and two of those (rs331932518, 5.69E-08 and rs344315078, 8.11E-10) detected in both results were located on $V W A 3 B$ and $N U A K 1$, respectively (Figure $5 \mathrm{C}$, $5 \mathrm{D}, 5 \mathrm{I}, 5 \mathrm{~J})$. In trait3, comparison of the two p.thresholds revealed no differences in 15 significant association signals and three genes (TENM3, NOL10 and PLCG2) were located on the known susceptibility loci according to these genomic positions (Figure 5E, 5F, 5K, 5L). Furthermore, the Q-Q plots of all these arithmetic values

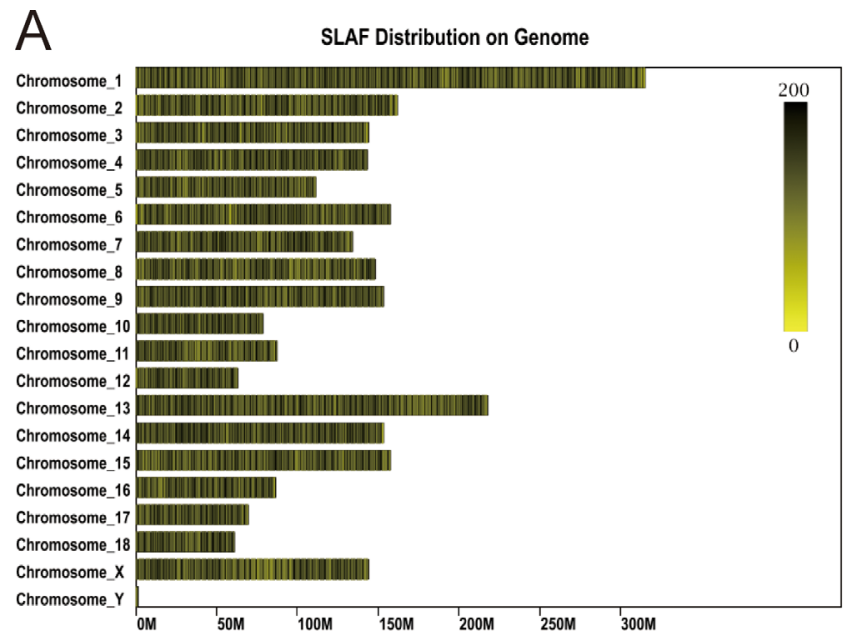

indicated that the GWAS with farmCPU could be used to accurately identify genes associated with inguinal/ scrotal hernias. In summary, we observed 14 known genes related to the susceptibility SNPs $(P \leq 7.76 \mathrm{E}-06)$ identified through GWAS, and four of them (TENM3, PLCG2, PRKCE and NUAK1) showed the strongest association signal $\left(P<10^{-9}\right)$ with the disease. From the results, the power of farmCPU was better than the case/ control model, which cannot completely distinguish the real signals from the background noise. With PLINK, only 2 candidate genes were identified, but 13 associated genes were identified using farmCPU, suggesting this method may be more suitable for the discovery of complex and polygenic traits.

\section{Confirmation of association results in $\mathbf{2 7 0}$ samples}

After the GWAS, 14 genes overlapping the candidate regions of 21 SNPs were discovered. To validate the SNPs associated with inguinal/scrotal hernias, we chose the most strongly associated SNPs and the genes that were shown to be related to cell apoptosis in previous studies for replication of the association signal. In total, 6 genes (CPNE5, DEGS1, PLCG2, PRKCE, NUAK1 and TENM3) were confirmed for further genotyping in 270 individuals. Furthermore, two strong candidate genes COL2A1 [27] and $M M P 2$ [28], which were proved to be associated with increased risk of inguinal/scrotal hernias in former studies were selected for the replication study to measure the relatedness with hernias in our group. Interestingly, the results in Table 4 show that 4 of 8 SNPs were significantly $(p<0.05)$ associated with the inguinal/scrotal hernia in 270 pigs. However, while using the purebred samples including the French Yorkshire and the French Landrace, the association was not significant all the time. In detail,

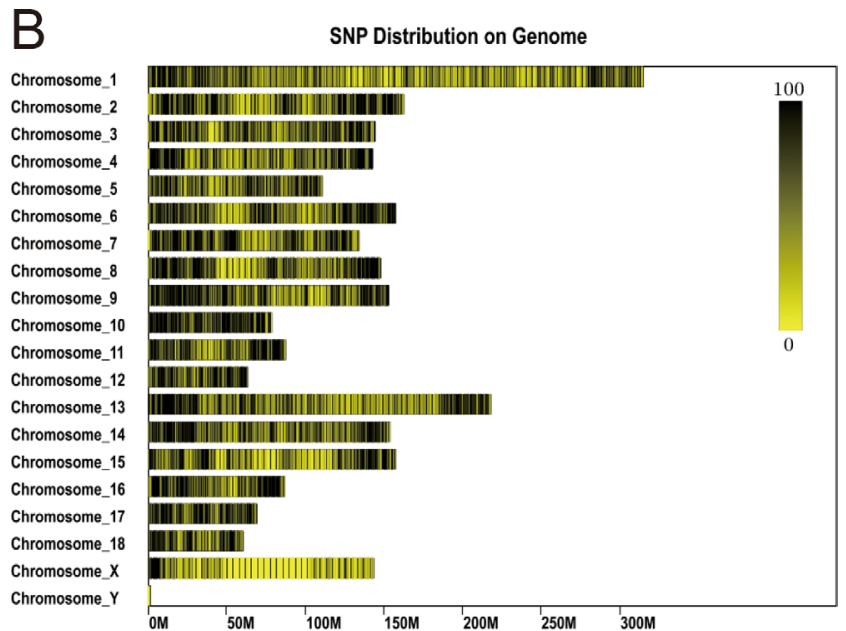

Figure 1: SLAF and SNP distribution on the 12 chromosomes of pigs. Horizontal lines represent chromosomes, with the chromosomal length on the x-axis. The scale in the top-right corner indicates the number of SLAFs or SNPs. All SLAFs (black lines) distributed on each chromosome (A). All SNPs (black lines) distributed on each chromosome (B). In each chromosome, the more the markers are, the darker the color is. 
Table 1: Significant association SNPs in the genome-wide association by PLINK for inguinal/ scrotal hernia

\begin{tabular}{ccccc}
\hline Chromosome & SNP name & Position (bp) & P value & Overlapped gene \\
\hline 1 & rs330433880 & 167390400 & $5.48 \mathrm{E}-06$ & \\
6 & rs324506705 & 84565388 & $7.33 \mathrm{E}-06$ & \\
6 & $\mathrm{rs332435472}$ & 84565401 & $3.95 \mathrm{E}-06$ & \\
6 & $\mathrm{rs} 705699393$ & 117226150 & $5.14 \mathrm{E}-06$ & \\
7 & $\mathrm{rs327702852}$ & 37402882 & $4.82 \mathrm{E}-06$ & CPNE5 \\
8 & $\mathrm{rs342486064}$ & 104820715 & $1.31 \mathrm{E}-06$ & \\
$X$ & $\mathrm{rs340140110}$ & 17669963 & $8.44 \mathrm{E}-06$ & MAP7D2 \\
\hline
\end{tabular}

CPNE5 (rs327702852) showed an extremely significant association with hernias in all the groups with a chisquared test $P$ value of $3.241 \mathrm{E}-07,0.001423(p<0.01)$ and $0.02066(p<0.05)$. Actually, CPNE5 (rs327702852) was the only one that showed the strongest signals in different breeds in our study, which indicated the CPNE5 gene may play an important role in the formation of an inguinal/scrotal hernia. Otherwise, three remarkable farmCPU-identified SNPs maintained genome-wide significant associations: TENM3 rs693312052 ( $p=$ $0.003708<0.01)$, PLCG2 rs336839455 $(p=0.02157$
$<0.05)$, PRKCE rs328681942 ( $p=0.01461<0.05)$. Specifically, TENM3 and PRKCE were also suggestively associated with hernias $(p=0.04922$ and 0.03025$)$ even in the purebred groups, i.e., French Landrace and French Yorkshire, respectively. Moreover, SNPs within the NUAK1 gene showed associations with only French Landrace but not with more pigs and it may be caused by the limited sample numbers. For the remaining three SNPs, the comparison in mixed or purebred groups did not uncover notable differences between inguinal/scrotal hernias and the polymorphisms of DEGS1, COL2A1 and
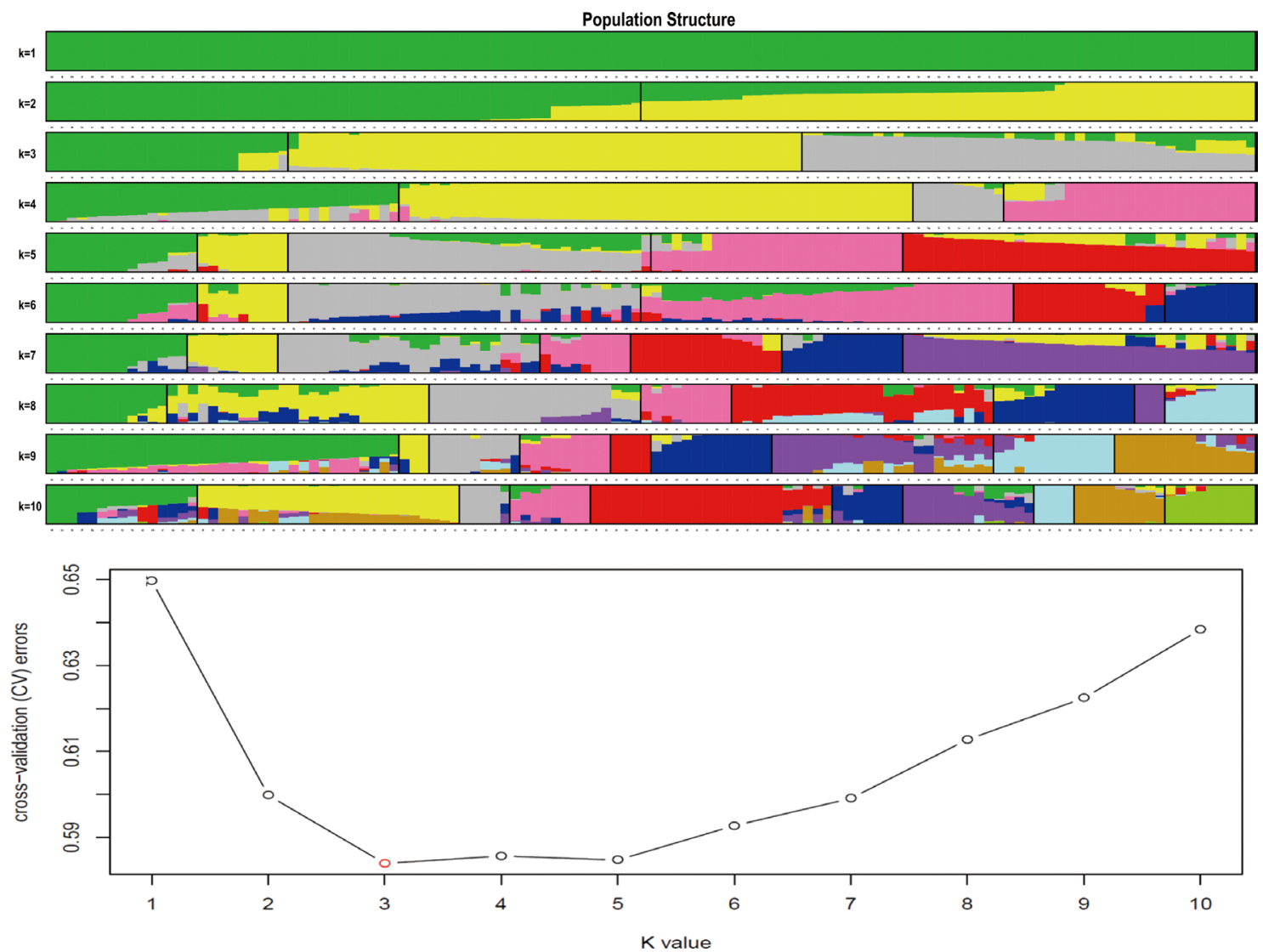

Figure 2: Population structure analysis in 120 accessions of pigs. In the upper panel, each color represents a group and each line represents a cluster and different colours represent separate groups. The lower panel displays the sub-group value, where the value ranges from 1 to 10 . The colored coefficient of variation $(\mathrm{CV})$ value for minimum $\mathrm{K}$ value $(\mathrm{K}=3)$ represents inferred membership in $\mathrm{K}$ genetic clusters. 
MMP2 $(p>0.05)$ providing some evidence that numerous SNPs in pig inguinal/scrotal hernias were likely breed specific, which coincided with the former studies of pig inguinal/scrotal hernias [29-31].

\section{DISCUSSION}

The SLAF-seq strategy, a novel NGS-based method, has been applied widely in de novo SNP discovery and genotyping of large populations [18], such as highdensity genetic map construction of cucumbers [32], candidate genes analysis of cotton [33], and high-quality SNP identification of rapeseed [34]. However, there have been few reports about the application of SLAFseq technology in resistance breeding of livestock, and to our best knowledge, this study is the first report of pig inguinal/scrotal hernias at genome-wide significance using SLAF-seq technology. Traditionally, the porcine SNP60K chip of Illumina was utilized to genotype samples $[35,36]$. Compared with the SLAF-seq technology, SNP chip cannot be used when a reference genome is unavailable, suggesting that only known SNP markers could be detected by SNP-arrays [37]. While the SLAFseq is designed to be independent of the reference genome, the new SNPs may be investigated and developed by this method [38]. In our study, the sequencing depth among each sample was $12.81 \mathrm{X}$, which revealed the overall coverage of the whole genome was more than $95 \%$ and the number of the called SNPs was 2,514,779, which was much higher than the number of the markers in previous studies that used the 60K SNP Beadchip (64,232 SNPs) [35].

To estimate the heritability of inguinal/scrotal hernias, a GWAS of pig inguinal/scrotal hernias was carried out after SLAF sequencing on these population of pigs. Initially, both the general linear model (GLM) and the mixed linear model (MLM) were used to seek the associated markers and allelic variation by TASSEL [39]. However, there was no clear signal associated with the hernia even when the cutoff $P$ value was $<0.05$. In consideration of different statistical models that tend to perform differently from various datasets [40], a case-control model implemented in PLINK, which has been previously reported [41], was employed to ascertain the remarkable SNPs associated with inguinal/scrotal hernias, and 7 significant association loci and 2 candidate genes (CPNE5, MAP7D2) were identified. Some studies have reported that case-control analysis by PLINK controlled the population structure and kinship among individuals as covariates to reduce false positives, but the use of covariates and testing markers may cause confounding, which could produce false negatives [42]. Interestingly, in addition to these classical models, farmCPU is a modern tool that can be used to effectively control the false positives in a genome-wide association study and completely eliminate the confounding problem in current methods [43]. Specifically, this method is divided into two parts as follows: a Fixed Effect Model (FEM) and a Random Effect Model (REM). Pseudo markers were calculated as covariates in FEM and optimized by REM to be designed to control false positives and even false negatives simultaneously [43]. FarmCPU, as an original statistic strategy, is equipped to significantly improve statistical power and speed, which successfully detected more QTNs than MLM under a low false discover rate in Arabidopsis thaliana and pigs [28]. Concretely, three more loci were identified for rupture of the cranial (anterior) cruciate ligament (RCCL) of complex orthopedic traits in dogs by farmCPU, which were not identified for RCCL in the previous report [44]. Avjinder S. detected 17 neverbefore-reported putative SNPs which were associated with soybean canopy wilting by farmCPU and these remarkable markers has been successfully used for identifying parental genotypes in breeding programs [43]. As these examples
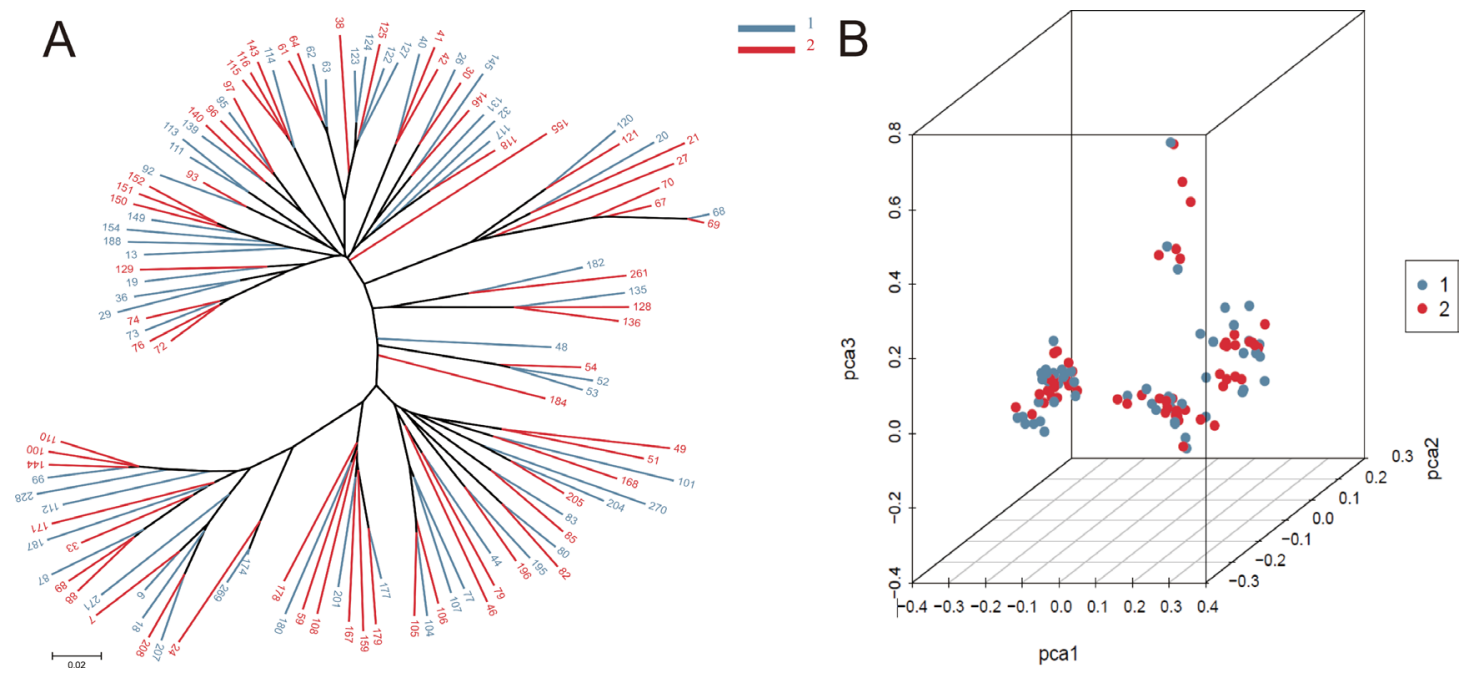

Figure 3: Characterization of the genetic structure of the 120 pig accessions. (A) The evolutionary tree of the 120 pig accessions based on the analysis of 218,460 SNPs. (B) PCA analysis of 120 pig accessions based on the analysis of 218,460 SNPs. The branch and point indicates each material. The blue line/point is materials who suffered inguinal/scrotal hernia, and red line/point is controls. 
Table 2: Significant association SNPs by farmCPU with $\mathrm{p}$.threshold $=0.01 / \mathrm{N}$ for inguinal $/$ scrotal hernia

\begin{tabular}{|c|c|c|c|c|c|}
\hline Trait & Chromosome & SNP name & Position (bp) & $P$ value & Overlapped gene \\
\hline 1 & 12 & rs324304114 & 34729146 & $1.19 \mathrm{E}-06$ & LOC102167662 \\
\hline 1 & 13 & rs344395079 & 202760816 & $1.74 \mathrm{E}-06$ & LOC100623424 \\
\hline 1 & 14 & rs319767757 & 3186015 & $1.24 \mathrm{E}-06$ & $A U H$ \\
\hline 1 & 14 & rs320497311 & 3186054 & 2.19E-06 & $A U H$ \\
\hline 1 & 8 & rs342486064 & 104820715 & $6.23 \mathrm{E}-08$ & LOC102167758 \\
\hline 1 & 8 & rs344971120 & 124744876 & $6.46 \mathrm{E}-06$ & \\
\hline 2 & 11 & rs333915086 & 79002243 & 8.91E-06 & \\
\hline 2 & 12 & rs707102499 & 7147387 & $4.56 \mathrm{E}-06$ & \\
\hline 2 & 13 & rs345544978 & 216120419 & $6.90 \mathrm{E}-06$ & $T M P R S S 3$ \\
\hline 2 & 13 & rs340959250 & 216123992 & $5.60 \mathrm{E}-06$ & TMPRSS3 \\
\hline 2 & 13 & rs703849339 & 216162734 & $6.90 \mathrm{E}-06$ & $U B A S H 3 A$ \\
\hline 2 & 13 & rs 327383802 & 216162735 & $6.90 \mathrm{E}-06$ & UBASH3A \\
\hline 2 & 13 & rs 340532657 & 216186419 & $2.33 \mathrm{E}-06$ & UBASH3A \\
\hline 2 & 13 & rs329192909 & 216186440 & $8.91 \mathrm{E}-07$ & UBASH3A \\
\hline 2 & 14 & rs691341365 & 96397595 & 7.76E-06 & PTPN20B \\
\hline 2 & 16 & rs695479999 & 3704632 & $2.78 \mathrm{E}-07$ & \\
\hline 2 & 3 & rs331932518 & 58618400 & $2.55 \mathrm{E}-06$ & $V W A 3 B$ \\
\hline 2 & 4 & rs326799532 & 72683195 & $5.69 \mathrm{E}-06$ & \\
\hline 2 & 5 & rs 344315078 & 14224907 & $1.35 \mathrm{E}-06$ & NUAK1 \\
\hline 2 & 9 & rs339050967 & 134709123 & $3.64 \mathrm{E}-06$ & \\
\hline 3 & 10 & rs341855439 & 45457399 & $3.49 \mathrm{E}-06$ & \\
\hline 3 & 10 & rs342639148 & 49056928 & $1.63 \mathrm{E}-06$ & \\
\hline 3 & 13 & rs 327747621 & 41755529 & $5.31 \mathrm{E}-06$ & LOC100737245 \\
\hline 3 & 14 & rs711689020 & 12819127 & $2.68 \mathrm{E}-07$ & \\
\hline 3 & 15 & rs693312052 & 50816340 & $2.26 \mathrm{E}-11$ & TENM3 \\
\hline 3 & 16 & rs329831629 & 13208012 & $1.29 \mathrm{E}-14$ & LOC102166550 \\
\hline 3 & 3 & rs 345757418 & 36050138 & $3.16 \mathrm{E}-09$ & LOC102163305 \\
\hline 3 & 3 & rs326409933 & 60432354 & $2.01 \mathrm{E}-06$ & \\
\hline 3 & 3 & rs343695952 & 134682302 & 4.60E-06 & NOL10 \\
\hline 3 & 3 & rs 337988450 & 134682458 & $4.60 \mathrm{E}-06$ & NOL10 \\
\hline 3 & 4 & rs320400918 & 62031612 & $6.60 \mathrm{E}-13$ & \\
\hline 3 & 6 & rs336839455 & 6997544 & $6.27 \mathrm{E}-10$ & PLCG2 \\
\hline 3 & 6 & rs333396283 & 88961742 & 4.61E-06 & \\
\hline 3 & 8 & rs 341737443 & 17618314 & $4.15 \mathrm{E}-07$ & \\
\hline 3 & 8 & rs320838432 & 115656516 & $3.43 \mathrm{E}-06$ & \\
\hline
\end{tabular}

suggest, farmCPU showed a stronger test power in different samples. Because it can effectively distinguish the associated markers between background noise above a strict control of error rate [45, 46]. More importantly, farmCPU has a higher test speed and a dataset with tens of thousands of markers can be analyzed in less than a week [47]. Therefore, we also performed a farmCPU analysis in order to verify more novel susceptibility loci for this complex disease. Based on this model, we confirmed 52 significant association loci and 12 candidate genes affecting inguinal/scrotal hernias in pigs utilizing the same data. The different results between these models further proved that farmCPU is an efficient tool for retrieving missed genes by other methods.

To date, many theories have intended to explain the etiology of inguinal/scrotal hernias and the most typical 
Table 3: Significant association SNPs by farmCPU with $\mathbf{p}$.threshold $=1 \mathrm{E}-05$ for inguinal/scrotal hernia

\begin{tabular}{|c|c|c|c|c|c|}
\hline Trait & Chromosome & SNP name & Position (bp) & $P$ value & Overlapped gene \\
\hline 1 & 11 & rs321121582 & 51457751 & $1.64 \mathrm{E}-07$ & \\
\hline 1 & 12 & rs324304114 & 34729146 & $8.64 \mathrm{E}-11$ & LOC102167662 \\
\hline 1 & 13 & rs344395079 & 202760816 & $1.89 \mathrm{E}-08$ & LOC100623424 \\
\hline 1 & 15 & rs341787989 & 123715674 & $4.81 \mathrm{E}-06$ & LOC102168011 \\
\hline 1 & 2 & rs321767225 & 120299079 & $5.86 \mathrm{E}-06$ & \\
\hline 1 & 3 & rs340228447 & 128504973 & $9.02 \mathrm{E}-10$ & \\
\hline 1 & 4 & rs331771053 & 133585924 & $9.05 \mathrm{E}-07$ & \\
\hline 1 & 8 & rs342486064 & 104820715 & $4.06 \mathrm{E}-12$ & LOC102167758 \\
\hline 1 & 9 & rs326461723 & 120701827 & $4.26 \mathrm{E}-07$ & LOC100625132 \\
\hline 2 & 1 & rs340355827 & 228307603 & $3.88 \mathrm{E}-09$ & \\
\hline 2 & 10 & rs342370930 & 14999738 & $1.71 \mathrm{E}-07$ & DEGS1 \\
\hline 2 & 12 & rs707102499 & 7147387 & $3.98 \mathrm{E}-11$ & \\
\hline 2 & 16 & rs337170191 & 7611324 & $8.69 \mathrm{E}-06$ & \\
\hline 2 & 3 & rs331932518 & 58618400 & $5.69 \mathrm{E}-08$ & $V W A 3 B$ \\
\hline 2 & 3 & rs322669192 & 100395213 & $6.05 \mathrm{E}-06$ & \\
\hline 2 & 3 & rs328681942 & 100554717 & $1.53 \mathrm{E}-09$ & PRKCE \\
\hline 2 & 3 & rs 329076481 & 100667390 & $1.11 \mathrm{E}-06$ & PRKCE \\
\hline 2 & 4 & rs326799532 & 72683195 & $2.56 \mathrm{E}-14$ & \\
\hline 2 & 5 & rs344315078 & 14224907 & $8.11 \mathrm{E}-10$ & NUAK1 \\
\hline 2 & 6 & rs321426177 & 125417548 & $5.76 \mathrm{E}-06$ & \\
\hline 2 & 6 & rs707167754 & 140966050 & $1.17 \mathrm{E}-06$ & \\
\hline 2 & 6 & rs322990991 & 155603932 & $1.66 \mathrm{E}-06$ & \\
\hline 2 & 8 & rs340232857 & 140425238 & $3.56 \mathrm{E}-06$ & $M E P E$ \\
\hline 3 & 10 & rs341855439 & 45457399 & $3.49 \mathrm{E}-06$ & \\
\hline 3 & 10 & rs342639148 & 49056928 & $1.63 \mathrm{E}-06$ & \\
\hline 3 & 13 & rs327747621 & 41755529 & $5.31 \mathrm{E}-06$ & LOC100737245 \\
\hline 3 & 14 & rs711689020 & 12819127 & $2.68 \mathrm{E}-07$ & \\
\hline 3 & 15 & rs693312052 & 50816340 & $2.26 \mathrm{E}-11$ & TENM3 \\
\hline 3 & 16 & rs329831629 & 13208012 & $1.29 \mathrm{E}-14$ & LOC102166550 \\
\hline 3 & 3 & rs345757418 & 36050138 & $3.16 \mathrm{E}-09$ & LOC102163305 \\
\hline 3 & 3 & rs326409933 & 60432354 & $2.01 \mathrm{E}-06$ & \\
\hline 3 & 3 & rs343695952 & 134682302 & 4.60E-06 & NOL10 \\
\hline 3 & 3 & rs337988450 & 134682458 & 4.60E-06 & NOL10 \\
\hline 3 & 4 & rs320400918 & 62031612 & $6.60 \mathrm{E}-13$ & \\
\hline 3 & 6 & rs336839455 & 6997544 & $6.27 \mathrm{E}-10$ & PLCG2 \\
\hline 3 & 6 & rs333396283 & 88961742 & 4.61E-06 & \\
\hline 3 & 8 & rs 341737443 & 17618314 & 4.15E-07 & \\
\hline 3 & 8 & rs320838432 & 115656516 & $3.43 \mathrm{E}-06$ & \\
\hline
\end{tabular}

hypotheses that were widely accepted were as follows: the apoptosis of muscle cells and aberrant collagen metabolism [30]. According to previous studies, the failure of incomplete closure of processus vaginalis and internal inguinal ring was thought to play an important role in the development of inguinal hernias and scrotal hernias, respectively $[48,49]$. Both pathological appearances were caused by dysfunction of smooth muscle, which was 
Table 4: Results of the further association analyses in 270 samples by chi square test of independence

\begin{tabular}{|c|c|c|c|c|}
\hline \multirow[t]{2}{*}{ Gene symbol } & \multirow[t]{2}{*}{ SNP } & $\begin{array}{l}\text { All samples } \\
(n=270)\end{array}$ & $\begin{array}{l}\text { French Yorkshire } \\
\qquad(n=111)\end{array}$ & $\begin{array}{c}\text { French Landrace } \\
(n=50)\end{array}$ \\
\hline & & $P$ value & $P$ value & $P$ value \\
\hline CPNE5 & $\mathrm{C} / \mathrm{T}$ & $3.241 \mathrm{E}-07$ & 0.001423 & 0.02066 \\
\hline TENM3 & $\mathrm{G} / \mathrm{T}$ & 0.003708 & 0.4291 & 0.04922 \\
\hline PLCG 2 & $\mathrm{C} / \mathrm{T}$ & 0.02157 & 0.3558 & 0.3371 \\
\hline PRKCE & $\mathrm{A} / \mathrm{G}$ & 0.01461 & 0.03025 & 0.9171 \\
\hline$N U A K 1$ & $\mathrm{C} / \mathrm{T}$ & 0.1589 & 0.1852 & 0.01644 \\
\hline$D E G S 1$ & $\mathrm{C} / \mathrm{T}$ & 0.2340 & 0.3735 & 0.3192 \\
\hline COL2A1 & $\mathrm{C} / \mathrm{T}$ & 0.2011 & 0.1662 & 0.2463 \\
\hline$M M P 2$ & $\mathrm{C} / \mathrm{T}$ & 0.9347 & 0.5556 & 0.6776 \\
\hline
\end{tabular}

achieved by cell apoptosis [50]. Compared with smooth muscle samples from controls, smooth muscle samples from patients with inguinal hernias failed to reveal the nucleolus of apoptotic cells and had lower levels of $\mathrm{Ca}^{2+}$, which is the key to programmed cell death [51]. In addition, abnormal collagen metabolism is strongly associated with hernia disease [52]. Collagen is the main protein for resisting stress because of its tensile strength and it is composed of some specific anatomical structures such as the internal inguinal ring and gubernaculums [30, 53]. Compared with the patients, more type III collagen, which is an immature collagen form of connective tissue, can be attributed to the development of hernias [53]. Thus, we propose that the genes related to collagen metabolism and apoptosis may be hernia-associated genes that contribute to the weakening of the abdominal wall and the failure of obliterative processus vaginalis. Further, to evaluate the association between the two genes detected in a previous study (COL2A1 and $M M P 2$ ) and inguinal/scrotal hernias in our samples, a chisquared test of independence on 270 individuals was carried out. As the results showed, there was no association between the two certified candidate genes (COL2A1 and MMP2) and inguinal/scrotal hernias in our samples, implying that the molecular mechanisms of pig inguinal/scrotal hernias

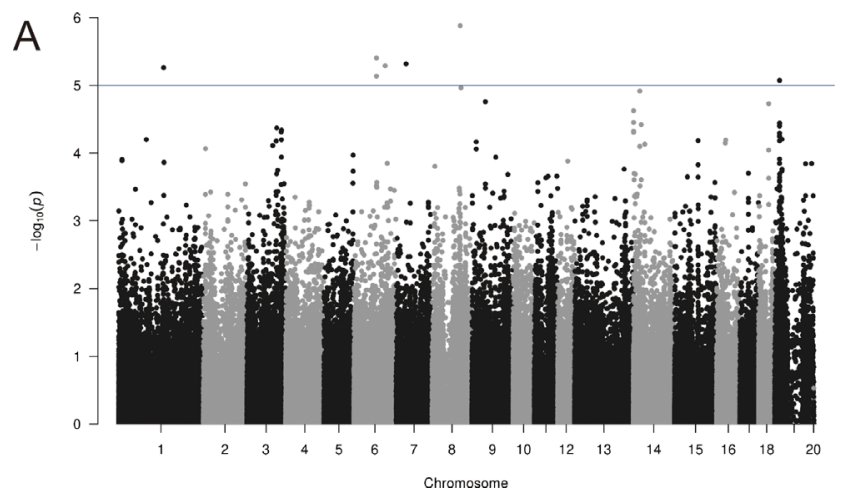

may be different in diverse pig breeds and lines. However, gene function classification of these loci revealed that five of the candidate genes (CPNE5, DEGS1, PLCG2, PRKCE and $N U A K 1$ ) were concerned with cell apoptosis, which was one of the possible pathogenesis factors for hernias in current studies. Thus, to evaluate the associations between the interesting genes in our study and inguinal/ scrotal hernias in pigs, a chi-squared test of independence on 270 individuals were carried out. In contrast, the genes confirmed in our study showed a strong association with inguinal/scrotal hernias and, more importantly, these genes were certified to take part in the apoptotic pathways in various reports. To be specific, the CPNE5 gene is in a novel family of ubiquitous $\mathrm{Ca}^{2+}$-dependent phospholipid-binding proteins and plays a key role in many processes of $\mathrm{Ca}^{2+}-$ mediated signal transduction, especially apoptosis [54]. It has been reported that the overexpression of the CPNE5 gene in HEK293 cells can cause cell death [55] and in early apoptosis of SH-SY5Y cells. The Cpne5 protein expression was significantly changed [56]. Similarly, the DEGS1 gene encoded a member of the membrane fatty acid desaturase family [57] and was proved to participate in the activation of caspase 9 and caspase 3 , which were marker proteins of cell apoptosis [58]. Moreover, PLCG2 and PRKCE genes

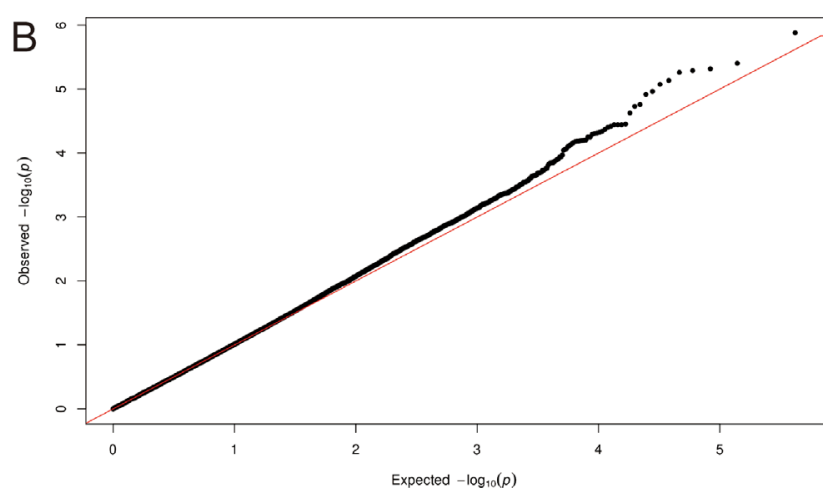

Figure 4: Manhattan plot (A) and quantile-quantile plot (B) of genome-wide association by PLINK for susceptibility to inguinal/scrotal hernia. The observed $-\log 10 p$-values (Y-axis) of the association between the SNPs and susceptibility for inguinal/scrotal hernia are shown. All SNP are represented by dots and displayed per chromosome (X-axis). The blue line shows the potential significance threshold:-log10 (E-05). 
A

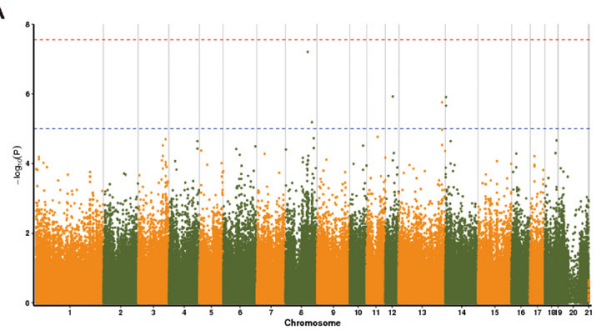

C

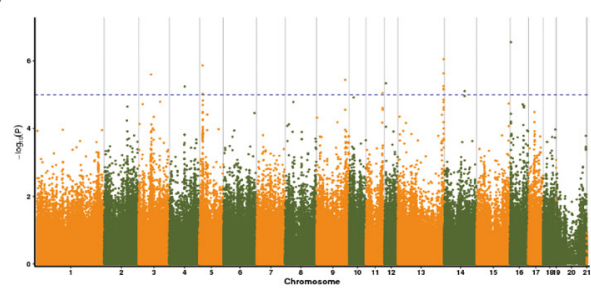

E

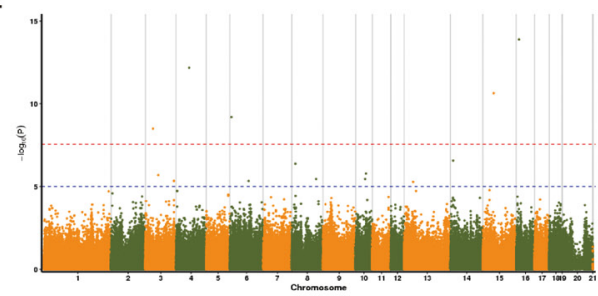

G

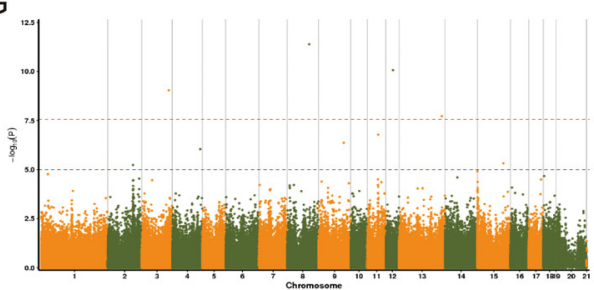

I

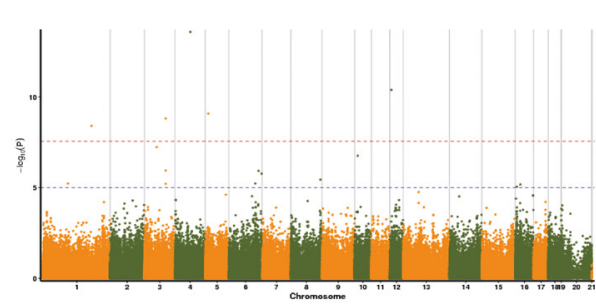

K

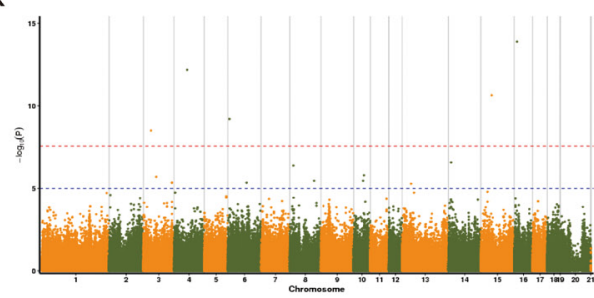

B

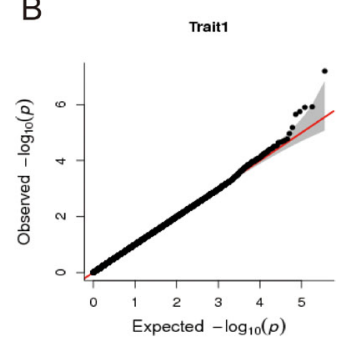

D Tratz

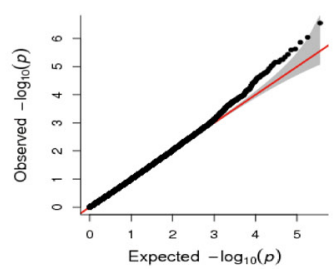

$\mathrm{F}$

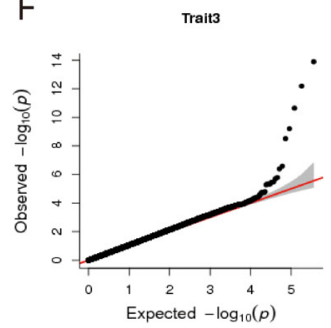

$\mathrm{H}$

H Trant

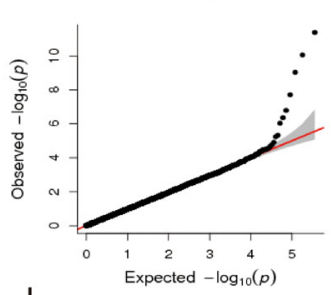

J Trait2

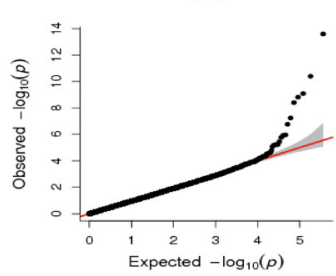

L

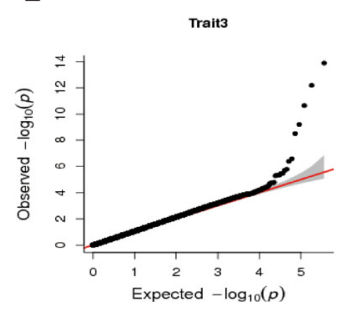

Figure 5: Manhattan and Quantile-quantile plots of genome-wide association by farmCPU for susceptibility to inguinal $/$ scrotal hernia. Manhattan plots with p.threshold $=0.01 / \mathrm{N}$ in trait1 (A), trait2 $(\mathbf{C})$, trait3 (E). Manhattan plots with p.threshold $=1 \mathrm{E}-05$ in trait1 $(\mathbf{G})$, trait2 (I), trait3 $(\mathbf{K})$. The observed $-\log 10 p$-values (Y-axis) of the association between the SNPs and susceptibility for inguinal/scrotal hernia are shown. All SNP are represented by dots and displayed per chromosome (X-axis). The blue line shows the potential significance threshold:- $\log 10$ (E-05), while the red shows the potential significance genome-wide significance threshold: $-\log 10$ (E-7.5). Quantile-quantile plot with p.threshold $=0.01 / \mathrm{N}$ in trait1 (B), trait2 (D), trait3 (F). Quantile-quantile plot with p.threshold $=1 \mathrm{E}-05$ in trait1 (H), trait2 (J), trait3 (L). 
encoded phospholipase C-(PLC) $\gamma 2$ and protein kinase $\mathrm{C}(\mathrm{PKC})-\varepsilon$, respectively, and both proteins were important elements of cellular signal transduction pathways that could regulate a chain of events either in physiological or pathological status [59-61]. Kajstura found that angiotensinconverting enzyme (ACE) II could induce the translocation of PKC- $\varepsilon$ of myocytes due to an increase in intracellular free $\mathrm{Ca}^{2+}$, which could lead to the initiation of apoptosis [62], while the translocation of PLC- $\gamma 2$ was certified to transmit the TPA signal to its downstream molecule PKC and directly promote the process of apoptosis in MGC80-3 cells [59]. Analogously, NUAK1, also known as AMPKrelated protein kinase 5, was the downstream molecule of Akt, which participated in the classical signaling pathway with extensive consequences [63]. Numerous studies have confirmed that Akt-ARK5 was closely related to cancer development and metastasis through blocking cell apoptosis by the inhibition of caspase 8 activation $[64,65]$. Based on the above information, the loci that we identified were more likely to be the true causal variant. Nonetheless, further investigation is needed to examine exactly how these SNPs affect disease or health by formal verification tools of biomedical research. For instance, We found that TENM3 gene is significantly correlated to inguinal/scrotal hernias $(P<0.01)$ in our samples and according to the JASPAR database, the SNP within TENM3 is found to be coincided with the DNA motifs to which the RUNX2 transcription factor bind. Therefore, a series of molecular biology assay are used to study the functions of TENM3 gene, hoping to confirm whether the TENM3 could be a candidate marker in marker-assisted selection breeding. Furthermore, some new methods (such as ISIS EMBLASSO) could be used in our dataset for detecting more significant loci of inguinal/ scrotal hernias.

In summary, we identified 59 SNPs significantly associated with inguinal/scrotal hernias, including 14 novel genes (CPNE5, MAP7D2, AUH, TMPRSS3, UBASH3A, PTPN20B, VWA3B, NOL10, DEGS1, MEPE, TENM3, PLCG2, PRKCE and NUAK1). To our knowledge, no studies investigating the associations of these SNPs with inguinal/scrotal hernias have been published. However, some SNPs that were previously identified as susceptibility loci were not detected. Moreover, the replication analyses supplied credible evidence for the association between gene polymorphisms concerning cell apoptosis and the risk of inguinal/scrotal hernias. Our findings could be useful for supplementing past studies of the etiology in pig inguinal/scrotal hernias and offer new evidence of genetic variation in this disease.

\section{MATERIALS AND METHODS}

\section{Ethics statement}

All animal experiments were conducted according to the regulations for the Administration of Laboratory
Animals of China. Animal experiments of our study were approved by the Animal Welfare Committee of Huazhong Agricultural University.

\section{Animals and sample preparation}

A total of 270 full and half sib pigs including 111 French Yorkshire pigs, 59 French Landrace pigs, 43 American Yorkshire pigs, 57 Duroc $\times$ Landrace $\times$ Yorkshire or Landrace $\times$ Yorkshire crossbred pigs, were obtained from the Kaisheng Pig Farm in Zhejiang, China. The samples consisted of 85 inguinal/scrotal hernia cases and 185 controls. In general, inguinal hernia and scrotal hernia cannot be easily distinguished without clinical examination. Both of them were diagnosed by palpation. For instance, an aberrant protrusion of abdominal or scrotum contents was found in pigs, and the protrusion may disappear when put up the legs slowly. Thus, the affected pigs were recorded as one kind of trait and the hernia phenotype was diagnosed carefully with palpation done by veterinarians. Finally, we selected 120 individuals consisting of 59 affected cases and 61 controls for SLAF sequencing.

The genomic DNA of all animals was extracted from porcine venous blood with a standard protocol with a Blood Genprep DNA Kit (Qiagen, USA), and all the DNA samples were diluted to a similar concentration. The quality and quantification of the genomic DNA were then estimated using $0.8 \%$ gel electrophoresis and a NanoDrop 2000 Spectrophotometer (Thermo Scientific, USA), respectively.

\section{SLAF library construction and sequencing}

One hundred and twenty pigs, including 59 cases and 61 controls, were used for SLAF library construction and sequencing, as described by Sun et al. [18]. Sequencing libraries of the samples were prepared through double digestion with the restriction enzymes RsaI and HaeIII (New England Biolabs, NEB, USA), which can digest pig genomic DNA into more than 300,000 sequencing tags of length 314-344 bp. Klenow Fragment $\left(3^{\prime} \rightarrow 5^{\prime}\right.$ exo-) (NEB) and dATP were used to add a single nucleotide (A) overhang to the digested fragments at $37^{\circ} \mathrm{C}$. Subsequently, T4 DNA ligase (NEB) was used to ligate the A-tailed fragments and the Duplex Tag-labeled Sequencing adapters (PAGE purified, Life Technologies, USA) [40]. Next, the DNA fragments were purified by Agencourt AMPure XP beads (Beckman Coulter, High Wycombe, UK). Finally, according to the manufacturer's recommendations, the gel purified product was sequenced using an Illumina HiSeq 2500 system (Illumina, Inc., San Diego, CA, USA) at Biomarker Technologies Co Ltd. in Beijing.

\section{SLAF-seq data analysis and SNP calling}

A total of 2,514,779 SNPs were remained for genome-wide association analysis. Before the association 
Table 5: SNP name, primers and restriction enzymes for PCR-RFLP and AS-PCR assays

\begin{tabular}{|c|c|c|c|}
\hline Gene & SNP & Primers sequence (5'-3') & Genotyping \\
\hline \multirow[t]{2}{*}{ CPNE5 } & $\mathrm{C} / \mathrm{T}$ & $\begin{array}{l}\text { Forward:TGTAATAATTGTCCCTCCTATGCTAC; } \\
\text { TAATAATTGTCCCTCCTATGCAGT }\end{array}$ & AS-PCR \\
\hline & & Reverse:CCTGGCTATTGTGAATAGTGCT & \\
\hline \multirow[t]{2}{*}{ TENM3 } & $\mathrm{G} / \mathrm{T}$ & Forward:GATCCTCTTATGGGAAAA & Sequencing \\
\hline & & Reverse:AACCTACTGACTGGGAGA & \\
\hline \multirow[t]{2}{*}{ PLCG2 } & $\mathrm{C} / \mathrm{T}$ & $\begin{array}{l}\text { Forward:GCCAGCTGCAGCTCAGCCCA; } \\
\text { TTTTAAGCCAGCTGCAGCTCAGAACG }\end{array}$ & AS-PCR \\
\hline & & Reverse:TTTGGTTGTGTCAGAGAGGAAAGGGTAAGAG & \\
\hline \multirow[t]{2}{*}{ PRKCE } & $\mathrm{A} / \mathrm{G}$ & Forward:ACCCTCAACGCTCTGTCC & TaqI ${ }^{\mathrm{a}}$ \\
\hline & & Reverse:TAGGCCGCTTAACCAAAA & \\
\hline \multirow[t]{2}{*}{ NUAK1 } & $\mathrm{C} / \mathrm{T}$ & $\begin{array}{l}\text { Forward:ACACCCCAGATGCTATCAGAACCACC; } \\
\text { CACACCCCAGATGCTATCAGAACCACT }\end{array}$ & AS-PCR \\
\hline & & Reverse:ACAATGGCTGGGGATCTAGAAGTGACAAG & \\
\hline \multirow[t]{2}{*}{ DEGS1 } & $\mathrm{C} / \mathrm{T}$ & Forward:TGACATGAGGCATCTTAGAGT & 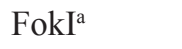 \\
\hline & & Reverse:GGAAGGGAAGTTCTTGGTAT & \\
\hline \multirow[t]{2}{*}{ COL2A1 } & $\mathrm{C} / \mathrm{T}$ & Forward: CCCATGCTGAGAAGCACTGA & $\mathrm{Bcn} \mathrm{I}^{\mathrm{a}}$ \\
\hline & & Reverse: GTGACCCACACTCCTGAAAG & \\
\hline \multirow[t]{2}{*}{$M M P 2$} & $\mathrm{C} / \mathrm{T}$ & Forward: AAAATGCTCTTCAGGCAGGA & BstAPI $^{\mathrm{a}}$ \\
\hline & & Reverse: AGGAGATGGGACTGGGAGTT & \\
\hline
\end{tabular}

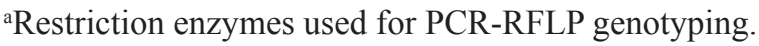

analysis, a systematic quality control (QC) procedure of SNPs was applied as follows: $\mathrm{Q}=-10 * \log _{10} \mathrm{e}$. Where $\mathrm{Q}$ is the quality value, and $\mathrm{e}$ is the error rate; if the error rate of sequencing is 0.001 , the quality of the quality value should be 30 . Thus, we selected $\mathrm{Q} \geq 30$ to inspect the quality of our sequencing. Meanwhile, the Short Oligonucleotide Alignment Program (SOAP) was used to map raw pairedend reads onto the reference genome [66]. The SLAFs mapped to the same position suggested high accuracy of the sequencing [67]. Then the consistent SNPs were called by the GATK [68] and SAMtools packages [67]. Ultimately, the intersection of these two methods were deemed as a true result and SNPs were selected with the criteria of minor allele frequency $(\mathrm{MAF})>0.05$ and integrity $>80 \%$.

\section{Evolutionary genetics analysis}

Based on the SNP genotype data identified in this study, phylogenetic trees were performed in MEGA5 software based on the neighbor-joining algorithm [66, 69], principal components analysis (PCA) was used by cluster software [68], and the population structure matrix was constructed in ADMIXTURE program using the maximum-likelihood method with 10,000 iterations [26]. $\mathrm{K}$, conducted by SPAGeDi [70] software, is the number of subgroups varying from 1 to 10 , and the minimum value according to the model choice criteria was considered the most likely value of ancestors from each $\mathrm{K}$ subgroup of each accession [71].

\section{GWAS analysis}

GWAS was carried out using two strategies based on case/control data. One was conducted by the PLINK v1.07 [72] software based on a case/control model. The genome-wide significance threshold, employed by Bonferroni-corrected $P$ values, was set as $0.1 / \mathrm{N}$, where N is the number of total SNPs used for GWAS.

The other strategy used a novel method, fixed and random model circulating probability unification (farmCPU), by farmCPU v1.0 [45]. Actually, farmCPU is a modified mixed linear model (MLM) that was designed to avoid the confounding problem of population structure and kinship. An additional function of farmCPU was to change the threshold by the parameter "p.threshold", when the genotypic markers are large. We set the p.threshold value as $1 \mathrm{E}-05$, when the $95 \%$ quantile value of each experiment is recommended for p.threshold. This threshold value is more stringent than that reported in other pig GWAS studies. Furthermore, to identify the common significant SNPs present in more than one trait, a default Bonferroni-corrected threshold value of $P=$ $0.01 / \mathrm{N}$ (where $\mathrm{N}$ is the number of total SNPs) was used. Both thresholds were used to indicate the association with the related traits. To obtain more high-quality statistical results, we divided the samples into three classes, named trait1, trait 2 and trait 3 . In all three kinds of traits, the 120 individuals were divided into 2 parts: cases and controls. Specifically, diseased or not could be the only factor 
considered in trait1. Moreover, trait 2 and trait 3 were also classified by pig breeds: trait 2 (Yorkshire, Landrace and crossbred) and trait3 (French lines and American lines). In sum, we analyzed the data using different classifications to get much greater statistical power by farmCPU.

Quantile-quantile (Q-Q) plots and Manhattan plots were implemented to check the veracity of these statistic parameters and obtain the visual results by $\mathrm{R}$ soft packages [73]. In this plot, each point represented a marker and the majority of the points should lie on the diagonal line, revealing no association with the trait. Only the point on the upper right section of the graph deviating from the diagonal could indicate that the SNP markers were most likely associated with the trait under study.

\section{Genotyping in 270 samples and statistical analysis}

To further validate the relevance between the identified SNPs and inguinal/scrotal hernias, genotyping of the screened SNPs of 270 pig samples was carried out by means of PCR-RFLP [74] AS-PCR [75] and a direct DNA sequencing method. Table 5 lists the oligonucleotide primers specific for candidate genes polymorphisms and the genotyping methods of each gene. For the RFLP analysis, we performed PCR reactions using $2 \times$ Taq PCR MasterMix (Aidlab, China) and the PCR temperature profile was as follows: $94^{\circ} \mathrm{C}$ for 3 minutes, 35 cycles of $94^{\circ} \mathrm{C}$ for 30 seconds, $55^{\circ} \mathrm{C}$ for 30 seconds, and $72^{\circ} \mathrm{C}$ for 30 seconds, followed by $72^{\circ} \mathrm{C}$ for 5 minutes. Then, the PCR products were digested with 10 units of each corresponding restriction endonuclease (RE) for more than 2 hours. The AS-PCR was performed with two sets of primers and the proportion of each of the components of the PCR mixture were the same as in the PCR method of PCR-RFLP. Finally, PCR and digestion products were separated directly by electrophoresis on $2 \%$ agarose gels (Biowest, Spain) and visualized under ultraviolet light.

The differences in the allele frequency among cases and controls were analyzed with a chi-squared test of independence via $\mathrm{R} 3.1 .1$ software [76]. If $p<0.05$, the results were considered statistically significant.

\section{ACKNOWLEDGMENTS AND FUNDING}

This study was supported by the National Key R\&D Program of China (2017YFD0400300) and the National Key Technology Support Program of China (2014BAD20B01).

\section{CONFLICTS OF INTEREST}

The authors declare no conflicts of interest.

\section{REFERENCES}

1. Szczesny W, Cerkaska K, Tretyn A, Dabrowiecki S. Etiology of inguinal hernia: ultrastructure of rectus sheath revisited. Hernia. 2006; 10:266-71. https://doi.org/10.1007/ s10029-006-0081-7.

2. Hutson JM, Temelcos C. Could inguinal hernia be treated medically? Medical Hypotheses. 2005; 64:37-40. https:// doi.org/10.1016/j.mehy.2003.11.046.

3. Clarnette TD, Hutson JM. Is the ascending testis actually 'stationary'? Normal elongation of the spermatic cord is prevented by a fibrous remnant of the processus vaginalis. Pediatr Surg Int. 1997; 12:155-7.

4. Beuermann C, Beck J, Schmelz U, Dunkelberg H, Schutz E, Brenig B, Knorr C. Tissue calcium content in piglets with inguinal or scrotal hernias or cryptorchidism. J Comp Pathol. 2009; 140:182-6. https://doi.org/10.1016/j. jcpa.2008.11.006.

5. Puri P. Failure of gubernacular development in the persistent mullerian duct syndrome allows herniation of the testes. Journal of Pediatric Surgery. 1995; 30:1105-6.

6. Skandalakis JE, Colborn GL, Skandalakis LJ. The embryology of the inguinofemoral area: an overview. Hernia. 1997; 1:45-54.

7. Beck J, Bornemann-Kolatzki K, Knorr C, Taeubert H, Brenig B. Molecular characterization and exclusion of porcine GUSB as a candidate gene for congenital hernia inguinalis/scrotalis. BMC Veterinary Research. 2006; 2:1-9.

8. Jorgenson E, Makki N, Shen L, Chen DC, Tian C, Eckalbar WL, Hinds D, Ahituv N, Avins A. A genome-wide association study identifies four novel susceptibility loci underlying inguinal hernia. Nat Commun. 2015; 6:10130. https://doi.org/10.1038/ncomms10130.

9. Germerodt M, Beuermann C, Rohrer GA, Snelling WM, Brenig B, Knorr C. Characterization and linkage mapping of 15 porcine STS markers to fine-map chromosomal regions associated with hernia inguinalis/scrotalis. Anim Genet. 2008; 39:671-2. https://doi.org/10.1111/j.13652052.2008.01779.x.

10. Zhao X, Du ZQ, Vukasinovic N, Rodriguez F, Clutter AC, Rothschild MF. Association of HOXA10, ZFPM2, and MMP2 genes with scrotal hernias evaluated via biological candidate gene analyses in pigs. Am J Vet Res. 2009; 70:1006-12. https://doi.org/10.2460/ajvr.70.8.1006.

11. Du ZQ, Zhao X, Vukasinovic N, Rodriguez F, Clutter AC, Rothschild MF. Association and haplotype analyses of positional candidate genes in five genomic regions linked to scrotal hernia in commercial pig lines. PLoS One. 2009; 4:e4837. https://doi.org/10.1371/journal.pone.0004837.

12. Ding NS, Mao HR, Guo YM, Ren J, Xiao SJ, Wu GZ, Shen HQ, Wu LH, Ruan GF, Brenig B. A genome-wide scan reveals candidate susceptibility loci for pig hernias in an intercross between White Duroc and Erhualian. Journal of Animal Science. 2009; 87:2469. 
13. Sevillano CA, Lopes MS, Harlizius B, Hanenberg EH, Knol EF, Bastiaansen JWM. Genome-wide association study using deregressed breeding values for cryptorchidism and scrotal/inguinal hernia in two pig lines. Genetics Selection Evolution. 2015; 47:18. https://doi.org/ARTN1810.1186/ s12711-015-0096-6.

14. Davey JW, Hohenlohe PA, Etter PD, Boone JQ, Catchen JM, Blaxter ML. Genome-wide genetic marker discovery and genotyping using next-generation sequencing. Nature Reviews Genetics. 2011; 12:499.

15. Liu L, Li Y, Li S, Hu N, He Y, Pong R, Lin D, Lu L, Law $\mathrm{M}$. Comparison of next-generation sequencing systems. J Biomed Biotechnol. 2012; 2012:251364. https://doi. org/10.1155/2012/251364.

16. Alonso N, Lucas G, Hysi P. Big data challenges in bone research: genome-wide association studies and nextgeneration sequencing. Bonekey Rep. 2015; 4:635. https:// doi.org/10.1038/bonekey.2015.2.

17. Chen Q, Ma Y, Yang Y, Chen Z, Liao R, Xie X, Wang Z, He P, Tu Y, Zhang X, Yang C, Yang H, Yu F, et al. Genotyping by genome reducing and sequencing for outbred animals. PLoS One. 2013; 8:e67500. https://doi.org/10.1371/journal. pone.0067500.

18. Sun XW, Liu DY, Zhang XF, Li WB, Liu H, Hong WG, Jiang CB, Guan N, Ma CX, Zeng HP, Xu CH, Song J, Huang L, et al. SLAF-seq: An Efficient Method of LargeScale De Novo SNP Discovery and Genotyping Using High-Throughput Sequencing. Plos One. 2013; 8:e58700. https://doi.org/ARTNe5870010.1371/journal.pone.0058700.

19. Harper AL, Trick M, Higgins J, Fraser F, Clissold L, Wells R, Hattori C, Werner P, Bancroft I. Associative transcriptomics of traits in the polyploid crop species Brassica napus. Nat Biotechnol. 2012; 30:798-802. https:// doi.org/10.1038/nbt.2302.

20. Wootton JC, Feng X, Ferdig MT, Cooper RA, Mu J, Baruch DI, Magill AJ, Su XZ. Genetic diversity and chloroquine selective sweeps in Plasmodium falciparum. Nature. 2002; 418:320-3. https://doi.org/10.1038/nature00813.

21. Zhang Y, Wang L, Xin H, Li D, Ma C, Ding X, Hong W, Zhang $\mathrm{X}$. Construction of a high-density genetic map for sesame based on large scale marker development by specific length amplified fragment (SLAF) sequencing. BMC Plant Biol. 2013; 13:141. https://doi. org/10.1186/1471-2229-13-141.

22. Wei Q, Wang Y, Qin X, Zhang Y, Zhang Z, Wang J, Li J, Lou Q, Chen J. An SNP-based saturated genetic map and QTL analysis of fruit-related traits in cucumber using specific-length amplified fragment (SLAF) sequencing. Bmc Genomics. 2014; 15:1158.

23. Zhao X, Han Y, Li Y, Liu D, Sun M, Zhao Y, Lv C, Li D, Yang Z, Huang L, Teng W, Qiu L, Zheng H, et al. Loci and candidate gene identification for resistance to Sclerotinia sclerotiorum in soybean (Glycine max L. Merr.) via association and linkage maps. Plant J. 2015; 82:245-55. https://doi.org/10.1111/tpj.12810.
24. Wang WH, Wang JY, Zhang T, Wang Y, Zhang Y, Han K. Genome-wide association study of growth traits in Jinghai Yellow chicken hens using SLAF-seq technology. Animal Genetics. 2015. http://doi.org/10.1111/age.12346. [Epub ahead of print]

25. Li Z, Wei SJ, Li HJ, Wu KL, Cai ZW, Li DF, Wei W, Li QF, Chen J, Liu HL, Zhang LF. Genome-wide genetic structure and differentially selected regions among Landrace, Erhualian, and Meishan pigs using specific-locus amplified fragment sequencing. Scientific Reports. 2017;7:10063. https://doi.org/ARTN1006310.1038/s41598-017-09969-6.

26. Li H, Durbin R. Fast and accurate short read alignment with Burrows-Wheeler transform. Bioinformatics. 2010; 26: $589-595$.

27. Grindflek E, Moe M, Taubert H, Simianer H, Lien S, Moen T. Genome-wide linkage analysis of inguinal hernia in pigs using affected sib pairs. Bmc Genetics. 2006; 7:25. https:// doi.org/Artn2510.1186/1471-2156-7-25.

28. Abci I, Bilgi S, Altan A. Role of TIMP-2 in fascia transversalis on development of inguinal hernias. J Invest Surg. 2005; 18:123-8. https://doi.org/10.1080/08941930590956147.

29. Zhao X, Du ZQ, Rothschild MF. An association study of 20 candidate genes with cryptorchidism in Siberian Husky dogs. J Anim Breed Genet. 2010; 127:327-31. https://doi. org/10.1111/j.1439-0388.2010.00859.x.

30. Zhao X. A candidate gene association study of cryptorchidism and scrotal hernia using canine and porcine models. Dissertations \& Theses - Gradworks. 2009.

31. Long Y, Su Y, Ai H, Zhang Z, Yang B, Ruan G, Xiao S, Liao $X$, Ren J, Huang L, Ding N. A genome-wide association study of copy number variations with umbilical hernia in swine. Anim Genet. 2016; 47:298-305. https://doi. org/10.1111/age.12402.

32. Xu X, Xu R, Zhu B, Yu T, Qu W, Lu L, Xu Q, Qi X, Chen $X$. A high-density genetic map of cucumber derived from Specific Length Amplified Fragment sequencing (SLAFseq). Front Plant Sci. 2014; 5:768. https://doi.org/10.3389/ fpls.2014.00768.

33. Su J, Pang C, Wei H, Li L, Liang B, Wang C, Song M, Wang H, Zhao S, Jia X, Mao G, Huang L, Geng D, et al. Identification of favorable SNP alleles and candidate genes for traits related to early maturity via GWAS in upland cotton. BMC Genomics. 2016; 17:687. https://doi. org/10.1186/s12864-016-2875-Z.

34. Zhou Q, Zhou C, Zheng W, Mason AS, Fan S, Wu C, Fu D, Huang Y. Genome-Wide SNP Markers Based on SLAF-Seq Uncover Breeding Traces in Rapeseed (Brassica napus L.). Front Plant Sci. 2017; 8:648. https://doi.org/10.3389/fpls.2017.00648.

35. Stinckens A, Janssens S, Spincemaille G, Buys N. A whole genome association study using the $60 \mathrm{~K}$ porcine SNP beadchip reveals candidate susceptibility loci for scrotal hernia in pigs. 62nd Annual Meeting of the European Federation of Animal Science; 2011. https://www.biw. kuleuven.be/GENLOG/Pigendef/PDF-Files/Stinckens $\% 20$ et\%20al._EAAP\%202011-1.pdf. 
36. Ramayo-Caldas Y, Castello A, Pena RN, Alves E, Mercade A, Souza CA, Fernandez AI, Perez-Enciso M, Folch JM. Copy number variation in the porcine genome inferred from a $60 \mathrm{k}$ SNP BeadChip. BMC Genomics. 2010; 11:593. https://doi.org/10.1186/1471-2164-11-593.

37. Clarke S, Stijn TV, Brauning R, Dodds K, Mcewan J. (2014). Genotyping-By-Sequencing (GBS) in Sheep: Comparison to SNP Chips and Whole Genome Sequencing. International Plant and Animal Genome Conference Xxii.

38. Zeng B, Yan HD, Liu XC, Zang WJ, Zhang AL, Zhou SF, Huang LK, Liu JP. Genome-wide association study of rust traits in orchardgrass using SLAF-seq technology. Hereditas. 2017;154:5. https://doi.org/ARTN510.1186/ s41065-017-0027-3.

39. Bradbury PJ, Zhang Z, Kroon DE, Casstevens TM, Ramdoss Y, Buckler ES. TASSEL: software for association mapping of complex traits in diverse samples. Bioinformatics. 2007; 23:2633-5.

40. Kozich JJ, Westcott SL, Baxter NT, Highlander SK, Schloss PD. Development of a dual-index sequencing strategy and curation pipeline for analyzing amplicon sequence data on the MiSeq Illumina sequencing platform. Applied \& Environmental Microbiology. 2013; 79:5112-20.

41. Miao YX, Soudy F, Xu Z, Liao MX, Zhao SH, Li XY. Candidate Gene Identification of Feed Efficiency and Coat Color Traits in a C57BL/6J x Kunming F2 Mice Population Using Genome-Wide Association Study. Biomed Research International. 2017;2017:7132941. https://doi.org/Artn713 294110.1155/2017/7132941.

42. Neale BM, Medland S, Ripke S, Anney RJ, Asherson P, Buitelaar J, Franke B, Gill M, Kent L, Holmans P, Middleton F, Thapar A, Lesch KP, et al. Case-control genome-wide association study of attention-deficit/hyperactivity disorder. J Am Acad Child Adolesc Psychiatry. 2010; 49:906-20. https://doi.org/10.1016/j.jaac.2010.06.007.

43. Kaler AS, Ray JD, Schapaugh WT, King CA, Purcell LC. Genome-wide association mapping of canopy wilting in diverse soybean genotypes. Theor Appl Genet. 2017;130:22032217. https://doi.org/10.1007/s00122-017-2951-z.

44. Huang M, Hayward JJ, Corey E, Garrison SJ, Wagner GR, Krotscheck U, Hayashi K, Schweitzer PA, Lust G, Boyko AR, Todhunter RJ. A novel iterative mixed model to remap three complex orthopedic traits in dogs. Plos One. 2017; 12:e0176932. https://doi.org/ARTNe017693210.1371/ journal.pone.0176932.

45. Liu X, Huang M, Fan B, Buckler ES, Zhang Z. Iterative Usage of Fixed and Random Effect Models for Powerful and Efficient Genome-Wide Association Studies. Plos Genetics. 2016; 12:e1005767.

46. Liu X. FarmCPU: An R Package of Genome-Wide Association Study for Big Data. Plant \& Animal Genome. 2015.

47. Tamba CL, Ni YL, Zhang YM. Iterative sure independence screening EM-Bayesian LASSO algorithm for multi-locus genome-wide association studies. Plos Computational Biology. 2017; $13: \mathrm{e} 1005357$.

48. Coveney D, Shaw G, Renfree MB. Effects of oestrogen treatment on testicular descent, inguinal closure and prostatic development in a male marsupial, Macropus eugenii. Reproduction. 2002; 124:73-83.

49. Diniz G, Aktas S, Ortac R, Yegane S. A comparative histopathological evaluation of sacs from boys and girls with inguinal hernia. Pathol Res Pract. 2004; 200:531-6. https://doi.org/10.1016/j.prp.2004.04.010.

50. Mouravas VK, Koletsa T, Sfougaris DK, Philippopoulos A, Petropoulos AS, Zavitsanakis A, Kostopoulos I. Smooth muscle cell differentiation in the processus vaginalis of children with hernia or hydrocele. Hernia. 2010; 14:187-91. https://doi.org/10.1007/s10029-009-0588-9.

51. Diaz R, Quiles MT, Guillem-Marti J, Lopez-Cano M, Huguet P, Ramon YCS, Reventos J, Armengol M, Arbos MA. Apoptosis-like cell death induction and aberrant fibroblast properties in human incisional hernia fascia. Am J Pathol. 2011; 178:2641-53. https://doi.org/10.1016/j. ajpath.2011.02.044.

52. Klinge U, Binnebösel M, Mertens PR. Are collagens the culprits in the development of incisional and inguinal hernia disease? Hernia the Journal of Hernias \& Abdominal Wall Surgery. 2006; 10:472-7.

53. Rosch R, Klinge U, Si Z, Junge K, Klosterhalfen B, Schumpelick V. A role for the collagen I/III and MMP$1 /-13$ genes in primary inguinal hernia? BMC Med Genet. 2002; 3:2.

54. Yan-Rui WU, Wang XW, Jin YB, Ding XF, Liu SH, Yan WU, Fan WH, Fan M. Effect of CPNE5 on transcriptional activity of NF- $\kappa$ B. Bulletin of the Academy of Military Medical Sciences. 2009.

55. Wang X, Wu Y, Jin Y, Ma X, Wu Y, Fan W, Fan M. CPNE5 expression induces ER stress in HEK293 cells. Bulletin of the Academy of Military Medical Sciences. 2007; 31:501-4.

56. Jin YB, Hui-Yuan SI, Yan-Ru WU, Ding XF, Wang XW, Fan WH. The Change of Cpne5 Protein Expression During SH-SY5Y Cell Apoptosis. Labeled Immunoassays \& Clinical Medicine. 2013; 20:427-430.

57. Zhou W, Ye XL, Sun ZJ, Ji XD, Chen HX, Xie D. (2009). Overexpression of degenerative spermatocyte homolog 1 up-regulates the expression of cyclin D1 and enhances metastatic efficiency in esophageal carcinoma Eca109 cells. Mol Carcinog. 2009; 48:886-94.

58. Zhu Q, Yang J, Zhu R, Jiang X, Li W, He S, Jin J. Dihydroceramide-desaturase-1-mediated caspase 9 activation through ceramide plays a pivotal role in palmitic acid-induced HepG2 cell apoptosis. Apoptosis. 2016; 21:1033.

59. Zhang B, Wu Q, Ye XF, Liu S, Lin XF, Chen MC. Roles of PLC-g2 and PKCa in TPA-induced apoptosis of gastric cancer cells. World Journal of Gastroenterology. 2003; 9:2413-8. 
60. Jun CD, Park SJ, Choi BM, Kwak HJ, Park YC, Kim MS, Park RK, Chung HT. Potentiation of the Activity of Nitric Oxide by the Protein Kinase C Activator Phorbol Ester in Human Myeloid Leukemic HL-60 Cells: Association with Enhanced Fragmentation of Mature Genomic DNA. Cellular Immunology. 1997; 176:41-9.

61. Lucas M, Sánchezmargalet V. Protein kinase C involvement in apoptosis. General Pharmacology. 1995; 26:881.

62. Kajstura J, Cigola E, Malhotra A, Li P, Cheng W, Meggs LG, Anversa P. Angiotensin II induces apoptosis of adult ventricular myocytes in vitro. Journal of Molecular \& Cellular Cardiology. 1997; 29:859.

63. Wang JW, Imai Y, Lu B. Activation of PAR-1 kinase and stimulation of tau phosphorylation by diverse signals require the tumor suppressor protein LKB1. Journal of Neuroscience. 2007; 27:574.

64. Ye XT, Guo AJ, Yin PF, Cao XD, Chang JC. Overexpression of NUAK1 is associated with disease-free survival and overall survival in patients with gastric cancer. Medical Oncology. 2014; 31:61.

65. Suzuki A, Kusakai G, Kishimoto A, Lu J, Ogura T, Esumi H. ARK5 suppresses the cell death induced by nutrient starvation and death receptors via inhibition of caspase 8 activation, but not by chemotherapeutic agents or UV irradiation. Oncogene. 2003; 22:6177.

66. Li R, Yu C, Li Y, Lam TW, Yiu SM, Kristiansen K, Wang J. SOAP2: an improved ultrafast tool for short read alignment. Bioinformatics. 2009; 25:1966-7. https://doi.org/10.1093/ bioinformatics/btp336.

67. Li H, Handsaker B, Wysoker A, Fennell T, Ruan J, Homer N, Marth G, Abecasis G, Durbin R, Genome Project Data Processing S. The Sequence Alignment/Map format and SAMtools. Bioinformatics. 2009; 25:2078-9. https://doi. org/10.1093/bioinformatics/btp352.

68. McKenna A, Hanna M, Banks E, Sivachenko A, Cibulskis K, Kernytsky A, Garimella K, Altshuler D, Gabriel S,
Daly M, DePristo MA. The Genome Analysis Toolkit: a MapReduce framework for analyzing next-generation DNA sequencing data. Genome Res. 2010; 20:1297-303. https:// doi.org/10.1101/gr.107524.110.

69. Arabidopsis Genome I. Analysis of the genome sequence of the flowering plant Arabidopsis thaliana. Nature. 2000; 408:796-815. https://doi.org/10.1038/35048692.

70. Hardy OJ, Vekemans X. spagedi: a versatile computer program to analyse spatial genetic structure at the individual or population levels. Molecular Ecology Resources. 2002; 2:618-20.

71. Yu J, Pressoir G, Briggs WH, Vroh BI, Yamasaki M, Doebley JF, Mcmullen MD, Gaut BS, Nielsen DM, Holland JB. A unified mixed-model method for association mapping that accounts for multiple levels of relatedness. Nature Genetics. 2006; 38:203.

72. Purcell S, Neale B, Todd-Brown K, Thomas L, Ferreira MA, Bender D, Maller J, Sklar P, de Bakker PI, Daly MJ. PLINK: A Tool Set for Whole-Genome Association and Population-Based Linkage Analyses. American Journal of Human Genetics. 2007; 81:559-75.

73. Knezevic SZ, Streibig JC, Ritz C. Utilizing R Software Package for Dose-Response Studies: The Concept and Data Analysis. Weed Technology. 2007; 21:840-8.

74. Olerup O, Zetterquist H. HLA-DR typing by PCR amplification with sequence specific primers (PCR-SSP) in 2 hours: an alternative to serological DR typing in clinical practice including donor-recipient matching in cadaveric transplantation. Tissue Antigens. 1992; 39:225-35.

75. Ugozzoli L, Wallace RB. Allele-specific polymerase chain reaction. Methods. 1991; 2:42-8.

76. Bradley DR, Bradley TD, Mcgrath SG, Cutcomb SD. Type I error rate of the chi-square test in independence in $\mathrm{R} \times \mathrm{C}$ tables that have small expected frequencies. Psychological Bulletin. 1979; 86:1290-7. 